\title{
Outcomes of Paraesophageal Hernia Repair: Analysis of the Veterans Affairs Surgical Quality Improvement Program Database
}

\author{
Sheena W. Chen ${ }^{1} \cdot$ Fred Brody $^{1} \cdot$ K. Benjamin Lee $^{1} \cdot$ Jarvis Walters $^{1} \cdot$ James Alex Randall $^{1}$ \\ Received: 2 October 2019 / Accepted: 13 May 2020 / Published online: 4 June 2020 \\ (C) 2020 The Society for Surgery of the Alimentary Tract (This is a U.S. government work and not under copyright protection in the U.S.; foreign copyright \\ protection may apply)
}

\begin{abstract}
Background While there have been many outcome studies on paraesophageal hernia repair in the civilian population, there is sparse recent data on the veteran population. This study analyzes the mortality and morbidities of veterans who underwent paraesophageal hernia repair in the Veterans Affairs Surgical Quality Improvement Program database.

Methods Veterans who underwent paraesophageal hernia repair from 2010 to 2017 were identified using Current Procedural Terminology codes. Multivariable analysis was used to compare laparoscopic and open, including abdominal and thoracic approaches, groups. The outcomes were postoperative complications and mortality.

Results There were 1607 patients in the laparoscopic group and 366 in the open group, with $84.1 \%$ men and mean age of 61 years. Gender and body mass index did not influence the type of surgical approach. The mortality rates at 30 and 180 days were $0.5 \%$ and $0.7 \%$, respectively. Postoperative complications, including reintubation (2.2\%), pneumonia (2.0\%), intubation > $48 \mathrm{~h}(2.0 \%)$, and sepsis $(2.0 \%)$ were higher in the open group $(15.9 \%$ versus $7.2 \%, p<0.001)$. The laparoscopic group had a significantly shorter length of stay ( 4.3 versus 9.6 days, $p<0.001$ ) and a lower percentage of return to surgery within 30 days $(3.9 \%$ versus $8.2 \%, p<0.001)$ than the open group. The ratio of open versus laparoscopic paraesophageal hernia repairs varied significantly by different Veterans Integrated Services Network regions.

Conclusions Veterans undergoing laparoscopic paraesophageal hernia repair experience similar outcomes as patients in the private sector. Veterans who underwent laparoscopic paraesophageal hernia repair had significantly less complications compared to an open approach even after adjusting for patient comorbidities and demographics. The difference in open versus laparoscopic practices between various regions requires further investigation.
\end{abstract}

Keywords Paraesophageal hernia repair · VASQIP · Outcomes · Laparoscopic repair · Open repair · Veterans integrated service network

\section{Introduction}

Paraesophageal hernia $(\mathrm{PEH})$ is an uncommon type of hiatal hernia that affects mostly female patients over the age of 60 in the civilian population. ${ }^{1-6}$ Despite the uncommon nature, patients with symptomatic PEHs usually undergo elective intervention when symptoms impinge upon their quality of life, or

Meeting presentation: ACS Clinical Congress 2019 podium presentation (10/30/2019 in San Francisco, CA)

Fred Brody

fredrick.brody@va.gov

1 Department of Surgery, Washington DC Veterans Affairs Medical Center, 50 Irving St NW, 2B-100, Washington, DC 20422, USA emergently, if the individual encounters symptoms of gastric volvulus or strangulation. ${ }^{7-9} \mathrm{PEH}$ are usually repaired through a laparotomy, left thoracotomy, or laparoscopically. Studies from the civilian population document significant decreases in perioperative mortality and morbidity in laparoscopic compared to open PEH repair. Over the past decade, the number of laparoscopic paraesophageal hernia repairs has surpassed the number of open paraesophageal hernia repairs in the private sector. ${ }^{1-6,10}$ However, there have not been any recent studies of paraesophageal hernia outcomes in the veteran population in the last decade.

The Veterans Affairs Surgical Quality Improvement Program (VASQIP) database is a nationwide database that provides unique details on each patient. This data is available from a single electronic medical record called the Computerized Patient Record System (CPRS) that has been 
implemented in all VA hospitals since 1999." As the veterans are predominantly male, this study provides a unique opportunity to analyze the outcomes of paraesophageal hernia repair in the male population. The VASQIP database allows a granular analysis of details such as the geographic location of the surgical facility and surgeon subspecialty versus the National Surgical Quality Improvement Program (NSQIP). Previous studies have demonstrated variations in healthcare utilization, medical management, preventative medicine, and surgical outcomes. ${ }^{12,13}$ This study aims to analyze the surgical outcomes of veterans who underwent PEH repair in the recent decade to elucidate any association between patient demographics, comorbidities, or geographic locations and morbidities.

\section{Methods}

\section{Patient Selection}

Veterans who underwent paraesophageal hernia repair from 2010 to 2017 were identified using Current Procedural Terminology (CPT) codes from the VASQIP database. CPT codes included 43332, 43333, 43334, 43335, 43336, and 43337 for open procedures (laparotomy, thoracotomy, or thoracoabdominal approaches) with or without mesh placement and 43281 and 43282 for laparoscopic procedures with or without mesh placement. Patients were grouped into open versus laparoscopic cohorts.

\section{Data Collection}

VASQIP data for each patient included age at the time of surgery, gender, ethnicity, body mass index (BMI), primary and secondary CPT codes, patient comorbidities, preoperative lab results, operative data, postoperative lab results, 30-day complications, 30-day mortality, 180-day mortality, hospital length of stay (LOS), surgeon specialty, and Veteran Affairs facility code.

\section{Outcomes}

The outcomes included postoperative complications, including LOS, return to the operating room (OR), postoperative myocardial infarction (MI), pulmonary embolism (PE), pneumonia, reintubation, ventilator dependence $>48 \mathrm{~h}$, blood transfusion, stroke, acute renal failure, deep vein thrombosis (DVT), sepsis, urinary tract infection (UTI), superficial surgical site infection (SSI), deep SSI, organ space SSI, dehiscence, Clostridium difficile (C. diff) colitis, and 30-day, 180-day, and total all-cause mortality. The postoperative complications are further grouped into severe complications (return to OR, postoperative MI, pulmonary embolism, pneumonia, reintubation, ventilator $>48 \mathrm{~h}$, stroke, sepsis, organ space SSI) and minor complications (UTI, superficial SSI, deep SSI, transfusion).

\section{Statistical Analysis}

Univariate analysis was used to compare the patient demographics, comorbidities, lab results, operative data, and postoperative outcomes between open and laparoscopic groups, open abdominal and open thoracic groups, and facilities with high volume of open cases versus facilities with low volume of open cases. Multivariable logistic regression analysis was performed to determine significant different outcomes between the two cohorts. A backward-elimination approach was used with purposeful selection adjusting for factors such as patient age, gender, BMI, cardiopulmonary comorbidities, operative time, and hospital LOS. Patients were sorted by VA facility codes into different Veterans Integrated Services Networks (VISN) regions. Chi-square analysis was performed to compare the differences in open versus laparoscopic case percentages between separate VISN divisions against the average across all VA hospitals in the USA. Statistical analysis was performed using JMP Pro 14 Software.

\section{Results}

\section{Patient Demographics and Comorbidities}

Between 2010 and 2017, there were 1607 patients (81.5\%) who underwent laparoscopic paraesophageal hernia repair (LPHR) and 366 patients (18.6\%) who underwent open paraesophageal hernia repair (OPHR) in the VA hospitals nationwide. Overall, $84.1 \%$ of the patients were male and $75.7 \%$ were Caucasian. The mean age was 61 years old with an average BMI of 29.2. Gender, race, or average BMI were comparable between open and laparoscopic groups, but patients in the open group were significantly older and had higher comorbidities such as chronic obstructive pulmonary disease (COPD), functional dependency, hypertension (HTN) requiring medication, and higher American Society of Anesthesiologists (ASA) score (Table 1). Notably, there was a higher chance of class III obesity (BMI $>40)$ in patients who underwent OPHR, though this was not statistically significant (Table 1).

\section{Operative Variables}

While the laparoscopic approach increased between 2010 and 2013 compared to 2014 and 2017 (83.6\% versus $78.4 \%, p=$ 0.003 ), OPHR cases remained stable between the first half and second half of the data. In the OPHR group, the majority of patients underwent PEH repair through a laparotomy $(66.4 \%)$ versus thoracotomy (19.7\%; Table 2). Overall, $33.1 \%$ of 
Table 1 Univariate analysis of preoperative variables between LPHR and OPHR groups

\begin{tabular}{|c|c|c|c|}
\hline Preoperative variable & LPHR $(n=1607)$ & OPHR $(n=366)$ & $p$ value \\
\hline Age & $60.7 \pm 12.8$ & $62.3 \pm 11.5$ & $0.02 *$ \\
\hline Sex (male) & $1344(83.6 \%)$ & $315(86.1 \%)$ & 0.25 \\
\hline Race & & & 0.34 \\
\hline Hispanic & $55(3.7 \%)$ & $21(6.1 \%)$ & \\
\hline American Indian or Alaska Native & $21(1.4 \%)$ & $3(0.9 \%)$ & \\
\hline African American & $118(8.0 \%)$ & $27(7.8 \%)$ & \\
\hline Asian or Pacific Islander & $4(0.3 \%)$ & 0 & \\
\hline Caucasian & $1218(82.7 \%)$ & $276(80.0 \%)$ & \\
\hline Unknown & $57(3.9 \%)$ & $18(5.2 \%)$ & \\
\hline Body mass index & $29.2 \pm 5.0$ & $29.1 \pm 5.2$ & 0.08 \\
\hline Underweight & $16.7 \pm 1.7(9 ; 0.5 \%)$ & $17.1 \pm 1.6(3 ; 0.8 \%)$ & \\
\hline Obese II & $37.1 \pm 1.3(135 ; 8.4 \%)$ & $36.8 \pm 1.5(27 ; 7.3 \%)$ & \\
\hline Obese III & $44.1 \pm 5.4(40 ; 2.5 \%)$ & $42.1 \pm 2.2(16 ; 4.3 \%)$ & \\
\hline History of stroke & $30(1.9 \%)$ & $3(0.8 \%)$ & 0.16 \\
\hline History of cardiac surgery & $85(5.3 \%)$ & $22(6.0 \%)$ & 0.58 \\
\hline History of myocardial infarction & $41(2.6 \%)$ & $6(1.6 \%)$ & 0.30 \\
\hline Congestive heart failure & $83(5.3 \%)$ & $10(2.8 \%)$ & 0.05 \\
\hline COPD & $205(12.8 \%)$ & $67(18.3 \%)$ & $0.005^{*}$ \\
\hline Diabetes & $58(3.6 \%)$ & $17(4.6 \%)$ & 0.61 \\
\hline Bleeding disorder & $48(3.0 \%)$ & $10(2.7 \%)$ & 0.80 \\
\hline Functional status & & & $0.02 *$ \\
\hline Independent & $1562(97.2 \%)$ & $346(94.5 \%)$ & \\
\hline Partially dependent & $36(2.2 \%)$ & $18(4.9 \%)$ & \\
\hline Totally dependent & $9(0.6 \%)$ & $2(0.6 \%)$ & \\
\hline Hypertension requiring medication & $923(57.4 \%)$ & $236(64.5 \%)$ & $0.01 *$ \\
\hline Smoker at time of surgery & $269(16.7 \%)$ & $68(18.6 \%)$ & 0.40 \\
\hline Weight loss greater than $10 \%$ & $59(3.7 \%)$ & $14(3.8 \%)$ & 0.89 \\
\hline ASA class & & & $<0.001 *$ \\
\hline 1 & $7(0.4 \%)$ & $0(0)$ & \\
\hline 2 & $423(26.3 \%)$ & $64(17.5 \%)$ & \\
\hline 3 & $1096(68.2 \%)$ & $273(74.6 \%)$ & \\
\hline 4 & $81(5.0 \%)$ & $29(7.9 \%)$ & \\
\hline Preop albumin & $3.95 \pm 0.46$ & $3.91 \pm 0.48$ & 0.17 \\
\hline Preop hematocrit & $41.4 \pm 4.6$ & $41.1 \pm 4.8$ & 0.32 \\
\hline
\end{tabular}

* Statistical significance with $p$ value less than 0.05 patients had PEH repair with mesh. The OPHR group had a significantly higher number of emergent cases (5.2\% versus $1.0 \%)$, longer operative times (3.9 h versus $3.7 \mathrm{~h}$ ), and more intraoperative red blood cell (RBC) transfusions (6.3\% versus $0.3 \%$ ) than LPHR group (Table 2 ).

\section{Postoperative Outcomes}

The overall mortality rate at 30 and 180 days was $0.51 \%$ and $0.71 \%$, respectively. After univariable analysis, there was no significant difference in mortality rate between the two groups ( $0.44 \%$ in LPHR versus $0.82 \%$ in OPHR, $p=0.357)$. The LPHR group had a significantly shorter LOS (4.3 days versus 9.6 days, $p<0.001$ ), lower postoperative blood transfusion
( $12 \%$ versus $23 \%, p<0.001)$, and higher postoperative hematocrit $(35.2 \%$ versus $31.4 \%, p<0.001)$ than the OPHR group (Table 3 ). The postoperative complications, including both severe and minor complications (return to the operating room within 30 days, reintubation, pneumonia, intubated for $>48 \mathrm{~h}$, sepsis, and superficial surgical site infection (SSI)) were higher in the OPHR group than the LPHR group (Table 3). With multivariable regression models adjusting for patient demographics and comorbidities, patients with open repair had significantly higher number of VASQIP complications ( $15.9 \%$ versus $7.2 \%$, OR 0.4 CI 95\% $0.27-0.61$, $p<0.001)$, return to operating room within 30 days $(8.2 \%$ versus $3.9 \%, 0.42$ CI $95 \% 0.25-0.73, p=0.002)$, and postoperative pneumonia (4.1\% versus $1.5 \%, 0.37$ CI $95 \% 0.15-$ 
Table 2 Univariate analysis of intraoperative variables between LPHR and OPHR groups

\begin{tabular}{lllr}
\hline Intraoperative variable & LPHR & OPHR & $p$ value \\
\hline $\begin{array}{llll}\text { Repair with mesh } \\
\text { Different open approaches }\end{array}$ & $551(34.3 \%)$ & $101(20.6 \%)$ & $0.014^{*}$ \\
$\quad$ Abdominal & & $243(66.4 \%)$ & \\
Thoracic & & $72(19.7 \%)$ & \\
$\quad$ Thoracoabdominal & $16(1.0 \%)$ & $19(5.2 \%)$ & $<0.001^{*}$ \\
Emergency cases & $3.65 \pm 1.57$ & $3.94 \pm 1.79$ & $0.004^{*}$ \\
Operative time (h) & & & \\
Surgeon specialty & $1319(82.1 \%)$ & $242(66.1 \%)$ & $<0.001^{*}$ \\
$\quad$ General surgery & $285(17.7 \%)$ & $122(33.3 \%)$ & \\
Thoracic surgery & & & \\
\hline
\end{tabular}

*Statistical significance with $p$ value less than 0.05

$0.82, p=0.014)$ than patients with laparoscopic repairs (Table 4).

Subanalysis in the open group showed no differences between abdominal approach versus thoracic approach in patient demographics, comorbidities, and postoperative complications (Table 5). Specifically, postoperative pulmonary complications, including postoperative pneumonia, reintubation, and ventilator dependence $>48 \mathrm{~h}$, were similar between the two groups $(11.11 \%$ in abdominal approach versus $8.33 \%$ in thoracic approach, $p=0.4994)$.

\section{Regional Analysis in Trend}

The number of patients who underwent OPHR and LPHR were sorted into regional VISN divisions and plotted in Fig 1. As noted previously, the open repair consists of $18.6 \%$ of paraesophageal hernia repairs nationwide. The regional percentage of OPHR ranges from 6.7 to $31.2 \%$ (Table 6) depending on the VISN. Chi-square analysis of regional percentage of OPHR versus national average showed that VISN $5(28.6 \%, p=0.045), 10(25 \%, p=0.026)$, and 15 $(31.2 \%, p=0.006)$ had significantly higher OPHR compared to the national average (Table 6). In VISN 5, VA hospitals in West Virginia $(59.3 \%, n=27)$ had a significantly higher
Table 3 Univariate analysis of postoperative variables between LPHR and OPHR groups

\begin{tabular}{|c|c|c|c|}
\hline Postoperative variable & LPHR $(n=1607)$ & OPHR $(n=366)$ & $p$ value \\
\hline Hospital length of stay & $4.3 \pm 5.6$ & $9.6 \pm 27.2$ & $<0.001 *$ \\
\hline 30-Day mortality & $7(0.4 \%)$ & $3(0.8 \%)$ & 0.36 \\
\hline All-Cause mortality & $11(0.7 \%)$ & $3(0.8 \%)$ & 0.73 \\
\hline Number of VASQIP complications & $115(7.2 \%)$ & $58(15.9 \%)$ & $<0.001 *$ \\
\hline Complication severity** & & & $<0.001 *$ \\
\hline Minor & $37(2.3 \%)$ & $33(9.0 \%)$ & $0.005^{*}$ \\
\hline Severe & $126(7.8 \%)$ & $56(15.3 \%)$ & $<0.001 *$ \\
\hline Return to OR & $63(3.9 \%)$ & $30(8.2 \%)$ & $<0.001 *$ \\
\hline Postop MI & $5(0.3 \%)$ & $1(0.3 \%)$ & $>0.99$ \\
\hline Postop pulmonary embolism & $20(1.2 \%)$ & $7(1.9 \%)$ & 0.32 \\
\hline Postop pneumonia & $24(1.5 \%)$ & $15(4.1 \%)$ & $0.001 *$ \\
\hline Reintubation & $30(1.9 \%)$ & $13(3.6 \%)$ & $0.05^{*}$ \\
\hline Ventilator $>48 \mathrm{~h}$ & $30(1.9 \%)$ & $11(3.0 \%)$ & 0.17 \\
\hline Postop stroke & $3(0.2 \%)$ & $1(0.3 \%)$ & 0.56 \\
\hline Postop acute renal failure & $3(0.2 \%)$ & $3(0.8 \%)$ & 0.08 \\
\hline Postop DVT & $6(0.4 \%)$ & $2(0.6 \%)$ & 0.65 \\
\hline Postop sepsis & $27(1.7 \%)$ & $12(3.3 \%)$ & $0.05 *$ \\
\hline Postop UTI & $13(0.8 \%)$ & $6(1.6 \%)$ & 0.14 \\
\hline Superficial SSI & $9(0.6 \%)$ & $7(1.9 \%)$ & $0.009 *$ \\
\hline Deep SSI & $3(0.2 \%)$ & $1(0.3 \%)$ & 0.56 \\
\hline Organ/space SSI & $12(0.8 \%)$ & $5(1.4 \%)$ & 0.25 \\
\hline Dehiscence & $3(0.2 \%)$ & $1(0.3 \%)$ & 0.56 \\
\hline C. diff colitis & $8(0.5 \%)$ & $3(0.8 \%)$ & 0.46 \\
\hline Postop transfusion & $12(0.8 \%)$ & $23(6.3 \%)$ & $<0.001 *$ \\
\hline
\end{tabular}

*Statistical significance with $p$ value less than 0.05

**Severe $=$ return to OR, postop MI, postop pulmonary embolism, postop pneumonia, reintubation, ventilator $>48 \mathrm{~h}$, postop stroke, postop sepsis, organ space SSI. Minor = postop UTI, superficial SSI, deep SSI, postop transfusion 
Table 4 Multivariable regression analysis of intraoperative variables between LPHR and OPHR groups
Table 5 Subanalysis showing no differences in postoperative morbidities between patients who underwent open abdominal approach versus open thoracic approach

\begin{tabular}{lcccc}
\hline Postoperative variable & LPHR $(n=1607)$ & OPHR $(n=366)$ & Odds ratio & Adjusted $p$ \\
\hline Number of VASQIP complications & $115(7.2 \%)$ & $58(15.9 \%)$ & $0.40[0.27-0.61]$ & $<0.001^{*}$ \\
Return to OR & $63(3.9 \%)$ & $30(8.2 \%)$ & $0.42[0.25-0.73]$ & $0.002^{*}$ \\
Postop MI & $5(0.3 \%)$ & $1(0.3 \%)$ & $0.55[0.03-10.2]$ & 0.69 \\
Postop pulmonary embolism & $20(1.2 \%)$ & $7(1.9 \%)$ & $0.37[0.13-1.05]$ & 0.06 \\
Postop pneumonia & $24(1.5 \%)$ & $15(4.1 \%)$ & $0.37[0.16-0.82]$ & $0.01 *$ \\
Reintubation & $30(1.9 \%)$ & $13(3.6 \%)$ & $0.56[0.26-1.18]$ & 0.13 \\
Ventilator $>48$ h & $30(1.9 \%)$ & $11(3.0 \%)$ & $0.76[0.32-1.77]$ & 0.52 \\
Postop stroke & $3(0.2 \%)$ & $1(0.3 \%)$ & $0.63[0.06-6.70]$ & 0.70 \\
Postop acute renal failure & $3(0.2 \%)$ & $3(0.8 \%)$ & $0.27[0.04-2.02]$ & 0.20 \\
Postop DVT & $6(0.4 \%)$ & $2(0.6 \%)$ & $0.50[0.09-2.69]$ & 0.42 \\
Postop sepsis & $27(1.7 \%)$ & $12(3.3 \%)$ & $0.51[0.24-1.07]$ & 0.08 \\
Postop UTI & $13(0.8 \%)$ & $6(1.6 \%)$ & $0.61[0.20-1.82]$ & 0.37 \\
Superficial SSI & $9(0.6 \%)$ & $7(1.9 \%)$ & $0.35[0.09-1.35]$ & 0.13 \\
Deep SSI & $3(0.2 \%)$ & $1(0.3 \%)$ & $0.82[0.04-16.3]$ & 0.90 \\
Organ/space SSI & $12(0.8 \%)$ & $5(1.4 \%)$ & $0.37[0.11-1.21]$ & 0.10 \\
Dehiscence & $3(0.2 \%)$ & $1(0.3 \%)$ & $0.07[0.01-2.42]$ & 0.14 \\
C. diff colitis & $8(0.5 \%)$ & $3(0.8 \%)$ & $0.70[0.14-3.54]$ & 0.67 \\
\hline
\end{tabular}

*Statistical significance with $p$ value less than 0.05

\begin{tabular}{llll}
\hline Postoperative variable & Open abdominal $(n=243)$ & Open thoracic $(n=72)$ & $p$ value \\
\hline Hospital length of stay & $7.5 \pm 7.5$ & $8.0 \pm 5.1$ & $<0.001^{*}$ \\
30-Day mortality & $3(1.2 \%)$ & $0(0.0 \%)$ & 1.000 \\
All-cause mortality & $3(1.2 \%)$ & $0(0.0 \%)$ & 1.000 \\
1+ NSQIP complications & $37(15.2 \%)$ & $14(19.4 \%)$ & 0.393 \\
Complication severity** & & & 0.474 \\
Minor & $16(6.5 \%)$ & $1(1.4 \%)$ & 0.134 \\
Severe & $39(16.1 \%)$ & $12(16.7 \%)$ & 0.900 \\
Return to OR & $23(9.5 \%)$ & $5(6.9 \%)$ & 0.509 \\
Postop MI & $1(0.4 \%)$ & $0(0.0 \%)$ & 1.000 \\
Postop pulmonary embolism & $5(2.1 \%)$ & $2(2.8 \%)$ & 0.661 \\
Postop pneumonia & $10(4.1 \%)$ & $5(6.9 \%)$ & 0.346 \\
Reintubation & $9(3.7 \%)$ & $1(1.4 \%)$ & 0.465 \\
Ventilator $>48$ h & $8(3.3 \%)$ & $0(0.0 \%)$ & 0.206 \\
Postop stroke & $1(0.4 \%)$ & $0(0.0 \%)$ & 1.000 \\
Postop acute renal failure & $2(0.8 \%)$ & $1(1.4 \%)$ & 0.542 \\
Postop DVT & $1(0.4 \%)$ & $1(1.4 \%)$ & 0.406 \\
Postop sepsis & $10(4.1 \%)$ & $0(0.0 \%)$ & 0.124 \\
Postop UTI & $5(2.1 \%)$ & $1(1.4 \%)$ & 1.000 \\
Superficial SSI & $5(2.1 \%)$ & $0(0.0 \%)$ & 0.592 \\
Deep SSI & $1(0.4 \%)$ & $0(0.0 \%)$ & 1.000 \\
Organ/space SSI & $4(1.7 \%)$ & $1(1.4 \%)$ & 1.000 \\
Dehiscence & $0(0.0 \%)$ & $1(1.4 \%)$ & 0.229 \\
C. diff colitis & $0(0.0 \%)$ & $2(2.8 \%)$ & 0.052 \\
Postop transfusion & $17(7.0)$ & $2(2.8)$ & 0.263 \\
\hline
\end{tabular}

*Statistical significance with $p$ value less than 0.05 
Fig. 1 Open versus laparoscopic paraesophageal hernia repair numbers by VISN divisions. Number of laparoscopic cases for each VISN labeled in black.

Number of open cases for each VISN labeled in white

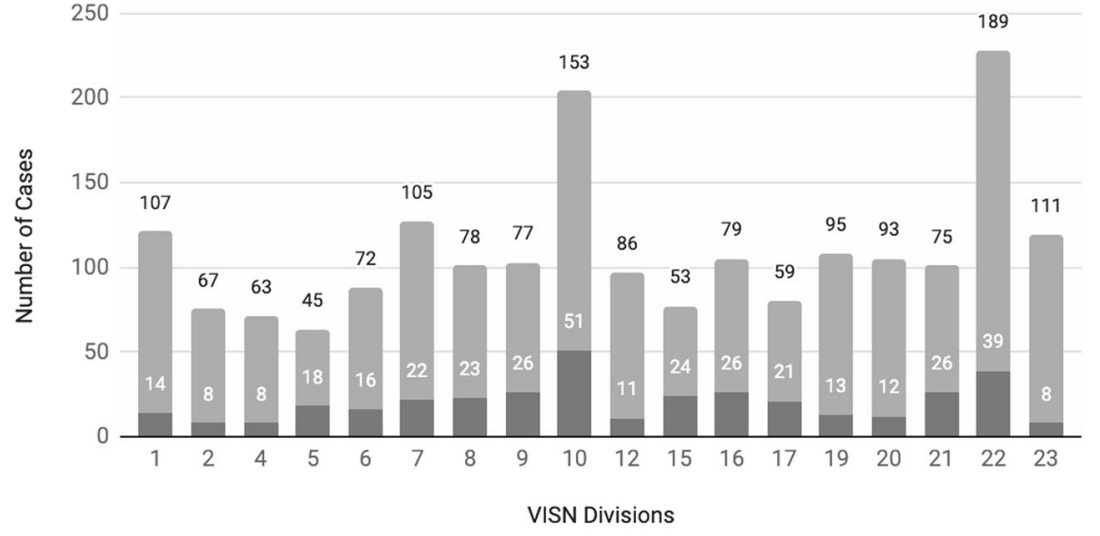

Legend:

Lap $\square$ Open percentage of OPHR $(59.3 \%, p<0.001)$ than the District of Columbia $(4.55 \%, n=22)$, Maryland $(7.1 \%, n=14)$, or Virginia $(11.8 \%, n=34)$. Mississippi had the highest percentage of OPHR in VISN 10 at $32.61 \%$ (46 cases), followed by Ohio (23.6\%, $n=106)$, Indiana $(21.2 \%, n=52)$, and Illinois $(20.6 \%, n=34)$. VISN 15 includes Missouri and Kansas with $31.3 \%$ and $30.8 \%$ of OPHR, respectively. On the other hand, VISN 23 in the Midwest had a significantly lower percentage of OPHR $(6.7 \%, p=0.001)$ in Minnesota, Iowa, North Dakota, South Dakota, and Nebraska (Fig. 2).

Analysis of surgeon specialty and surgical approach showed that LPHR were performed primarily by general surgeons, with $17.8 \%$ of laparoscopic repairs performed by thoracic surgeons nationally. The percentage of LPHR completed by thoracic surgeons ranges from $0 \%$ in numerous states to $86.3 \%$ in Connecticut (19 out of 22 cases). OPHR were coded mostly under general surgery $(66.3 \%)$, with general surgeons performing $78.1 \%$ through an abdominal approach, $5.0 \%$ through a thoracic approach, and $16.9 \%$ via a thoracoabdominal approach. Of note, all OPHR in Connecticut ( 6 cases) and Delaware ( 1 case) were performed by thoracic surgeons, regardless of the types of approach. There was no correlation of surgeon specialties with states that had significantly higher percentages of OPHR. For example, OPHR in West Virginia and Connecticut was performed $100 \%$ by general surgeons while $94 \%$ (14 out of 15 cases) were performed by thoracic surgeons in Georgia, regardless of approaches.
Table 6 Chi-square analysis of regional versus national open repair percentage

\begin{tabular}{lcccc}
\hline VISIN number and names & OPHR & LPHR & $\%$ OPHR & $p$ value \\
\hline 1: VA New England Healthcare System & 14 & 107 & $11.6 \%$ & 0.053 \\
2: New York/New Jersey VA Health Care Network & 8 & 67 & $10.7 \%$ & 0.083 \\
4: VA Healthcare & 8 & 63 & $11.3 \%$ & 0.119 \\
5: VA Capitol Health Care Network & 18 & 45 & $28.6 \%$ & $0.045^{*}$ \\
6: VA Mid-Atlantic Health Care Network & 16 & 72 & $18.2 \%$ & 0.930 \\
7: VA Southeast Network & 22 & 105 & $17.3 \%$ & 0.729 \\
8: VA Sunshine Healthcare Network & 23 & 78 & $22.8 \%$ & 0.289 \\
9: VA MidSouth Healthcare Network & 26 & 77 & $25.2 \%$ & 0.091 \\
10: VA Healthcare System & 51 & 153 & $25.0 \%$ & $0.026^{*}$ \\
12: VA Great Lakes Health Care System & 11 & 86 & $11.3 \%$ & 0.073 \\
15: VA Heartland Network & 24 & 53 & $31.2 \%$ & $0.006^{*}$ \\
16: South Central VA Health Care Network & 26 & 79 & $24.8 \%$ & 0.113 \\
17: VA Heart of Texas Health Care Network & 21 & 59 & $26.3 \%$ & 0.084 \\
19: Rocky Mountain Network & 13 & 95 & $12.0 \%$ & 0.088 \\
20: Northwest Network & 12 & 93 & $11.4 \%$ & 0.065 \\
21: Sierra Pacific Network & 26 & 75 & $25.7 \%$ & 0.072 \\
22: Desert Pacific Healthcare Network & 39 & 189 & $17.1 \%$ & 0.595 \\
23: VA Midwest Health Care Network & 8 & 111 & $6.7 \%$ & $0.001^{*}$ \\
\hline
\end{tabular}

*Statistical significance with $p$ value less than 0.05 


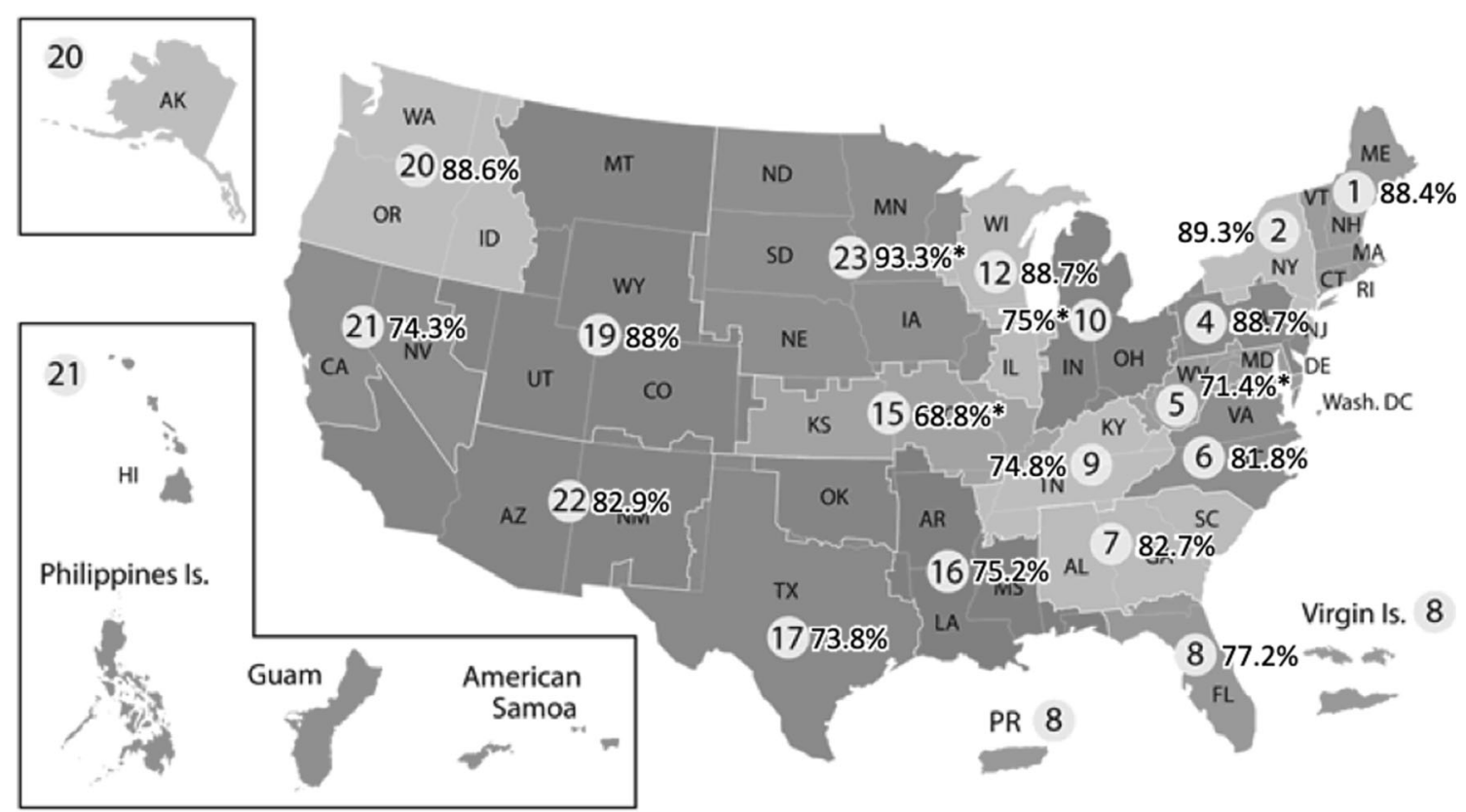

Fig. 2 Map of Veterans Integrated Service Networks (VISNs) with percent of laparoscopic repairs. *Statistical significance with $p$ value $<0.05$

Further analysis of facilities that had significantly higher rates of open versus laparoscopic PEHR, selected by facilities with greater than 5 open cases and greater than $50 \%$ open versus laparoscopic approach ( $>2$ standard deviation above national average), demonstrated no difference in the outcomes of open cases performed in facilities with higher rates of open repairs compared to the national average (Table 7). Of note, facilities that perform significantly higher rates of open cases had a shorter open operative time compared to their laparoscopic cases, though not statistically different $(3.81 \pm 1.79 \mathrm{~h}$ versus $3.93 \pm 1.70 \mathrm{~h}, p=0.705$ ). Table 8 compares the open PEHR outcomes of high volume facilities to the low volume facilities (defined as less than 5 cases and $<18.6 \%$ open cases, national average). There were no differences between the patient comorbidities and postoperative outcomes besides higher rate of postoperative UTI in facilities with lower volume of open PEHR (Table 8).

\section{Discussion}

This retrospective study of the VASQIP database is the first analysis of paraesophageal hernia repair short-term outcomes in the veteran population. Patients who underwent laparoscopic paraesophageal hernia repair had lower morbidities and mortalities than the open repair group which is consistent with publications in the civilian population. ${ }^{1-6}$

The VASQIP database provides a special opportunity to analyze paraesophageal hernia repair outcomes in a predominantly male veteran patient population compared to a majority of female patients undergoing PEH repair $(>60 \%)$ in the private sector. ${ }^{1-6}$ Presently, veterans are primarily Caucasian males over the age of 60 . As veterans have a higher rate of smoking than the average American, the number of tobacco smokers at the time of surgery $(17.1 \%)$ and consequently patients with COPD (13.8\%) were higher than that reported in the civilian population $(9.7 \%$ tobacco smoker and $5.6 \%$ COPD). ${ }^{3}$ Compared to the mostly female patient population in the NSQIP database, veterans who underwent paraesophageal hernia repair were more likely to have chronic heart failure (CHF), history of myocardial infarction (MI), prior cardiac surgery, and alcohol abuse. ${ }^{3}$

Despite increased comorbidities in the veteran population, paraesophageal hernia repair outcomes at VA hospitals are comparable to approaches and outcomes in the private sector. Mungo et al. analyzed PEH repair outcomes in the NSQIP database from 2005 to 2011 with a total 8186 patients (78.4\% LPHR, 19.2\% transabdominal OPHR, 2.4\% transthoracic OPHR). ${ }^{3}$ This study demonstrated that VA hospitals have adopted laparoscopic paraesophageal hernia repair with similar rates, including $81.5 \%$ of LPHR, $12.3 \%$ transabdominal OPHR, $3.6 \%$ transthoracic OPHR, and $2.6 \%$ thoracoabdominal OPHR. Moreover, the 30-day mortality rates were $0.4 \%$ in the LPHR group and $0.8 \%$ in the OPHR group, which are lower than the NSQIP database analysis that reported a 30-day mortality of $0.5 \%$ in the LPHR group and $4.1 \%$ in the OPHR group. ${ }^{3}$ The mortality rates in the VASQIP database may be lower than large database analysis due to the overall smaller sample size of OPHR. Also, our data is more recent than other database studies from two decades ago which may simply reflect better postoperative intensive care programs. $^{1-3}$

LPHR consistently provides significantly shorter LOS, decreased postoperative pain, and fewer perioperative 
Table 7 Differences in preoperative patient variables, operative time, and postoperative morbidities between patients who underwent OPHR at facilities that have a high rate of open cases versus the national average

\begin{tabular}{|c|c|c|c|}
\hline $\begin{array}{l}\text { Preop and postoperative } \\
\text { variables }\end{array}$ & $\begin{array}{l}\text { High open facility cases } \\
(n=87)\end{array}$ & $\begin{array}{l}\text { Nationwide open cases } \\
(n=366)\end{array}$ & $\begin{array}{l}p \\
\text { value }\end{array}$ \\
\hline Age & $60.7 \pm 11.8$ & $62.3 \pm 11.5$ & 0.235 \\
\hline Gender (male) & $70(80.5 \%)$ & $315(86.1 \%)$ & 0.186 \\
\hline BMI & $29.2 \pm 5.4$ & $29.1 \pm 5.2$ & 0.873 \\
\hline History of stroke & $3(3.5 \%)$ & $3(0.8 \%)$ & 0.186 \\
\hline History of cardiac surgery & $2(2.3 \%)$ & $22(6.0 \%)$ & 0.166 \\
\hline History of MI & $1(1.2 \%)$ & $6(1.6 \%)$ & 0.758 \\
\hline $\mathrm{CHF}$ & $1(1.2 \%)$ & $10(2.8 \%)$ & 0.375 \\
\hline COPD & $14(16.1 \%)$ & $67(18.3 \%)$ & 0.629 \\
\hline Diabetes & $9(10.3 \%)$ & $17(4.6 \%)$ & $0.038 *$ \\
\hline Alcohol abuse & $2(2.3 \%)$ & $11(3.0 \%)$ & 0.725 \\
\hline HTN requiring medication & $53(60.92 \%)$ & $236(64.5 \%)$ & 0.533 \\
\hline Current smoker & $15(17.24 \%)$ & $68(18.6 \%)$ & 0.769 \\
\hline Operative time & $3.81 \pm 1.79$ & $3.94 \pm 1.79$ & 0.543 \\
\hline Perioperative transfusions & $2(2.3 \%)$ & $23(6.3 \%)$ & 0.143 \\
\hline Return to OR & $6(6.9 \%)$ & $30(8.2 \%)$ & 0.687 \\
\hline Cardiac arrest & $1(1.2 \%)$ & $3(0.8 \%)$ & 0.752 \\
\hline Postop MI & $0(0 \%)$ & $1(0.3 \%)$ & 0.609 \\
\hline Postop PE & $1(1.2 \%)$ & $7(1.9 \%)$ & 0.633 \\
\hline Postop pneumonia & $3(3.5 \%)$ & $15(4.1 \%)$ & 0.781 \\
\hline Reintubation & $2(2.3 \%)$ & $13(3.6 \%)$ & 0.545 \\
\hline Ventilator $>48$ & $2(2.3 \%)$ & $11(3.0 \%)$ & 0.725 \\
\hline Postop stroke & $0(0 \%)$ & $3(0.8 \%)$ & 0.403 \\
\hline Postop sepsis & $3(3.5 \%)$ & $12(3.3 \%)$ & 0.944 \\
\hline Postop UTI & $0(0 \%)$ & $6(1.6 \%)$ & 0.236 \\
\hline Superficial SSI & $0(0 \%)$ & $7(1.9 \%)$ & 0.196 \\
\hline Deep SSI & $0(0 \%)$ & $1(0.3 \%)$ & 0.609 \\
\hline Organ/space SSI & $1(1.2 \%)$ & $5(1.4 \%)$ & 0.856 \\
\hline Dehiscence & $0(0 \%)$ & $1(0.3 \%)$ & 0.609 \\
\hline LOS & $7.41 \pm 6.39$ & $9.6 \pm 27.2$ & 0.456 \\
\hline
\end{tabular}

*Statistical significance with $p$ value less than 0.05 complications in the literature. ${ }^{1-6}$ After adjusting for patient comorbidities and operative variables, multivariable regression analysis showed that patients undergoing an open repair had significantly higher number of VASQIP complications, specifically a higher chance of returning to the operating room within 30 days, intraoperative and postoperative blood transfusions, and postoperative pneumonia than the LPHR group. Although an analysis of the Nationwide Inpatient Sample (NIS) database from 1999 to 2008 reported that thoracotomy PEH repairs had the longest length of stay and increased rate of prolonged postoperative ventilator use and pulmonary embolism, the rate of postoperative pulmonary complications in this database did not differ between the types of surgical approach (Table 5). ${ }^{1}$

LPHR can be technically challenging, but laparoscopic repairs have become the standard of care and are offered to elderly patients with significant comorbidities and in emergent settings. ${ }^{14,15}$ The laparoscopic approach not only had less postoperative morbidities and mortalities, it had significantly less operative time and intraoperative blood transfusion than open repairs (Table 2). The trend from open to laparoscopic repairs in the private sector has been replicated in the VA hospitals with increasing numbers of LPHR. ${ }^{1-6}$

The majority of VA hospitals provide laparoscopic paraesophageal hernia repair as the standard of care, while there are VA hospitals in certain regions of the country that perform a higher percentage of open repairs. The VASQIP database provided a unique opportunity to investigate the trends in regional practice since each patient entry is accompanied by a VA hospital facility code. Chi-Square analysis highlighted VISN 5, 10, and 15 with a significantly higher percentage of OPHR and VISN 23 had a significantly lower percentage than the national average. The difference between regions is often associated with a few outlying facilities. 
Table 8 Comparison of open paraesophageal hernia repair outcomes in facilities with high volume ( $>50 \%$ OPHR to LPHR ratio and overall $>5$ cases) of open cases versus low volume facilities $(<18 \%$ OPHR to LPHR ratio)

\begin{tabular}{|c|c|c|c|}
\hline $\begin{array}{l}\text { Pre- and postoperative } \\
\text { variables }\end{array}$ & $\begin{array}{l}\text { High open volume facilities } \\
(n=87)\end{array}$ & $\begin{array}{l}\text { Low open volume facilities } \\
(n=82)\end{array}$ & $\begin{array}{l}p \\
\text { value }\end{array}$ \\
\hline Age & $60.7 \pm 11.8$ & $61.0 \pm 11.7$ & 0.8684 \\
\hline Gender (male) & $70(80.5 \%)$ & $73(89.0 \%)$ & 0.127 \\
\hline BMI & $29.2 \pm 5.4$ & $28.9 \pm 5.2$ & 0.679 \\
\hline History of stroke & $3(3.5 \%)$ & $0(0 \%)$ & 0.088 \\
\hline History of MI & $1(1.2 \%)$ & $2(2.4 \%)$ & 0.557 \\
\hline $\mathrm{CHF}$ & $1(1.2 \%)$ & $3(3.7 \%)$ & 0.291 \\
\hline COPD & $14(16.1 \%)$ & $19(23.2 \%)$ & 0.246 \\
\hline Diabetes & $9(10.3 \%)$ & $7(8.5 \%)$ & 0.697 \\
\hline Alcohol abuse & $2(2.3 \%)$ & $1(1.2 \%)$ & 0.589 \\
\hline HTN requiring medication & $53(60.9 \%)$ & $39(47.6 \%)$ & 0.084 \\
\hline Current smoker & $15(17.2 \%)$ & $15(18.3 \%)$ & 0.852 \\
\hline Operative time & $3.81 \pm 1.79$ & $3.96 \pm 1.86$ & 0.594 \\
\hline Postoperative transfusions & $2(2.3 \%)$ & $0(0 \%)$ & 0.168 \\
\hline Return to OR & $6(6.9 \%)$ & $7(8.54 \%)$ & 0.690 \\
\hline Postop MI & $0(0 \%)$ & $1(1.2 \%)$ & 0.307 \\
\hline Postop PE & $1(1.2 \%)$ & $2(2.4 \%)$ & 0.557 \\
\hline Postop pneumonia & $3(3.5 \%)$ & $6(7.3 \%)$ & 0.274 \\
\hline Reintubation & $2(2.3 \%)$ & $2(2.4 \%)$ & 0.966 \\
\hline Ventilator $>48$ & $2(2.3 \%)$ & $4(4.8 \%)$ & 0.379 \\
\hline Postop stroke & $0(0 \%)$ & $0(0 \%)$ & - \\
\hline Postop sepsis & $3(3.5 \%)$ & $4(4.8 \%)$ & 0.672 \\
\hline Postop UTI & $0(0 \%)$ & $4(4.8 \%)$ & $0.039 *$ \\
\hline Superficial SSI & $0(0 \%)$ & $2(2.4 \%)$ & 0.147 \\
\hline Deep SSI & $0(0 \%)$ & $0(0 \%)$ & - \\
\hline Organ/space SSI & $1(1.2 \%)$ & $1(1.2 \%)$ & 1.000 \\
\hline Dehiscence & $0(0 \%)$ & $0(0 \%)$ & - \\
\hline LOS & $7.41 \pm 6.39$ & $8.80 \pm 10.16$ & 0.286 \\
\hline
\end{tabular}

*Statistical significance with $p$ value less than 0.05
Specifically, facilities 581 and 540 in West Virginia (VISN 5) had $56.5 \%$ (13 OPHR out of 23 total cases) and $100 \%$ ( 3 out of 3 cases) of OPHR, respectively. On the other hand, facility 437 in North Dakota (VISN 23) performed 95.5\% LPHR (64 out of 67 cases). Facilities that performed higher rates of open cases had a shorter open operative time compared to laparoscopic cases $(3.81 \pm 1.79 \mathrm{~h}$ versus $3.93 \pm 1.70 \mathrm{~h}, p=0.705)$, suggesting that surgeons at these facilities are more adept at open than laparoscopic PEHR. However, the perioperative outcomes remain the same as the national average or facilities that had low volume of open PEHR. These outcomes are worse than the laparoscopic outcomes, however (Tables 7 and 8). This data further highlights the differences in regional practices.

Technical approaches by surgical subspecialties varied significantly between states. Paraesophageal repairs in Connecticut were performed mostly by thoracic surgeons regardless of surgical approaches (86\% of LPHR and $100 \%$ of OPHR), compared to $100 \%$ of repairs completed by general surgeons in Colorado, District of Columbia, Kansas, Maine, Montana, Nebraska, Nevada, New Jersey, Virginia, North Dakota, Puerto Rico, and West Virginia. This data shows that the surgical subspecialty and approaches varied arbitrarily by different facilities and may indicate that surgical approach depends on the surgeon's practice pattern and training.

\section{Limitations}

This study has a few limitations as a retrospective database study. Due to the limitation of the variables in the database, we cannot be certain that patients who met the inclusion criteria for the study did not have a prior paraesophageal hernia repair. A prior hernia repair may sway the decision for the type of surgical approach and increase operative risk. In addition, the database was unable to discern the rationale behind elective open paraesophageal hernia repair approach. The database could not differentiate if the surgical approach was dictated by surgeon preference, adhesions from prior surgeries, or 
anatomic considerations. As patient demographics did not vary significantly across regions, the number of open procedures in certain regions in the United States remained relatively high. This may indicate that the type of surgical approach is more likely due to surgeon preference and not anatomical considerations or adhesive disease. Lastly, this database does not provide detailed follow-up to analyze any symptom or radiographic recurrence. This data would be valuable information in the future to document the true value of each operative approach.

\section{Conclusion}

Veterans undergoing LPHR experience similar outcomes and the same benefits as patients in the private sector. The results document that Veterans should be offered a laparoscopic approach to paraesophageal repair regardless of BMI or age. The differences in the percentage of open paraesophageal hernia repair between various regions appear to be driven by surgeon preference and not patient demographics or comorbidities.

Acknowledgments VA Informatics and Computing Infrastructure (VINCI) and VA National Surgery Office (NSO) information systems technicians and staff, Washington DC VA Medical center biostatistician David Maron, Washington DC VA Medical Center Institutional Review Board (IRB), and Office of Research and Development (ORD).

Disclaimer The contents do not represent the views of VA or the US Government.

Author Contributions Sheena W Chen: design, data acquisition, analysis, interpretation, drafting, critical revision, final approval. Fred Brody: design, data acquisition, interpretation, drafting, critical revision, final approval. K Benjamin Lee: design, data acquisition, analysis, interpretation, critical revision, final approval. Jarvis Walters: design, data interpretation, critical revision, final approval. James Alex Randall: data interpretation, critical revision, final approval. All authors agree to be accountable for all aspects of the work.

\section{References}

1. Paul S, Nasar A, Port JL, et al. Comparative analysis of diaphragmatic hernia repair outcomes using the nationwide inpatient sample database. Archives of surgery. 2012 Jul 1;147(7):607-12.

2. Fullum TM, Oyetunji TA, Ortega G, et al. Open versus laparoscopic hiatal hernia repair. Journal of the Society of Laparoendoscopic Surgeons. 2013 Jan; 17(1):23.
3. Mungo B, Molena D, Stem M, et al. Thirty-day outcomes of paraesophageal hernia repair using the NSQIP database: should laparoscopy be the standard of care? Journal of the American College of Surgeons. 2014 Aug 1;219(2):229-236.

4. Luketich JD, Nason KS, Christie NA, et al. Outcomes after a decade of laparoscopic giant paraesophageal hernia repair. The Journal of thoracic and cardiovascular surgery. 2010 Feb 1;139(2):395-404.

5. Oelschlager BK, Pellegrini CA, Hunter J, et al. Biologic prosthesis reduces recurrence after laparoscopic paraesophageal hernia repair: a multicenter, prospective, randomized trial. Annals of surgery. 2006 Oct;244(4):481.

6. Oelschlager BK, Pellegrini CA, Hunter JG, et al. Biologic prosthesis to prevent recurrence after laparoscopic paraesophageal hernia repair: long-term follow-up from a multicenter, prospective, randomized trial. Journal of the American College of Surgeons. 2011 Oct 1;213(4):461-8.

7. Yates RB, Oelschlager BK, Pellegrini CA. Gastroesophageal Reflux Disease and Hiatal Hernia. In: Townsend C, Beauchamp R, Evers B, Mattox K. Sabiston textbook of surgery: the biological basis of modern surgical practice. 20th ed. Philadelphia: Elsevier Saunders. 2017: Chapter 42: 1043-1064.

8. Meneshian A. The Management of Paraesophageal Hiatal Hernia. In: Cameron JL, Cameron AM, eds. Current Surgical Therapy. 12th ed. Philadelphia: Elsevier Mosby; 2017:32-35.

9. Skinner, David B. 1967. Surgical management of esophageal reflux and hiatus hernia: long-term results with 1,030 patients. Journal of Thoracic Cardiovasc Surgery 53: 33-54.

10. Schauer PR, Ikramuddin S, McLaughlin RH, Graham TO, Slivka A, Lee KK, Schraut WH, Luketich JD. Comparison of laparoscopic versus open repair of paraesophageal hernia. The American journal of surgery. 1998: 176(6):659-665.

11. Evans DC, Nichol WP, Perlin JB. Effect of the implementation of an enterprise-wide Electronic Health Record on productivity in the Veterans Health Administration. Health Economics, Policy and Law. 2006:163-169

12. Maciejewski ML, Arterburn DE, Berkowitz TS, Weidenbacher HJ, Liu CF, Olsen MK, Funk LM, Mitchell JE, Smith VA. Geographic variation in obesity, behavioral treatment, and bariatric surgery for veterans. Obesity. 2019:161-5.

13. Wilt TJ, Cowper DC, Gammack JK, Going DR, Nugent S, Borowsky SJ. An evaluation of radical prostatectomy at Veterans Affairs Medical Centers: time trends and geographic variation in utilization and outcomes. Medical care. 1999 Oct 1:1046-56.

14. Hazebroek EJ, Gananadha S, Koak Y, et al. Laparoscopic paraesophageal hernia repair: quality of life outcomes in the elderly. Diseases of the Esophagus. 2008 Nov 1;21(8):737-741.

15. Louie BE, Blitz M, Farivar AS, et al. Repair of symptomatic giant paraesophageal hernias in elderly ( $>70$ years) patients results in improved quality of life. Journal of Gastrointestinal Surgery. 2011 Mar 1;15(3):389-96.

Publisher's Note Springer Nature remains neutral with regard to jurisdictional claims in published maps and institutional affiliations. 